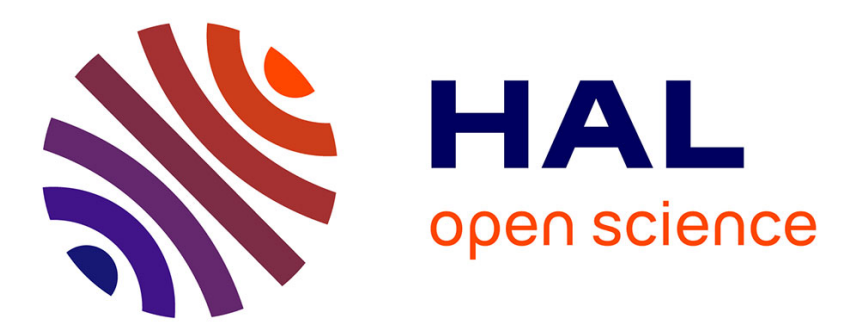

\title{
What Vilfredo Pareto brought to the economics of knowledge
}

Ludovic Ragni

\section{To cite this version:}

Ludovic Ragni. What Vilfredo Pareto brought to the economics of knowledge. Arena Richard, Festré Agnes, Lazaric Nathalie. Handbook of Knowledge and Economics, Edward Elgar, pp.23-48, 2012. halshs-01097720

\section{HAL Id: halshs-01097720 \\ https://shs.hal.science/halshs-01097720}

Submitted on 21 Dec 2014

HAL is a multi-disciplinary open access archive for the deposit and dissemination of scientific research documents, whether they are published or not. The documents may come from teaching and research institutions in France or abroad, or from public or private research centers.
L'archive ouverte pluridisciplinaire HAL, est destinée au dépôt et à la diffusion de documents scientifiques de niveau recherche, publiés ou non, émanant des établissements d'enseignement et de recherche français ou étrangers, des laboratoires publics ou privés. 


\section{Handbook of Knowledge and Economics}

Edited by

Richard Arena

Professor of Economics, University of Nice-Sophia Antipolis/ GREDEG - UMR 7321, France

Agnès Festré

Professor of Economics, University of Picardie Jules Vernel CRIISEA and University of Nice-Sophia Antipolis/ GREDEG - UMR 7321, France

Nathalie Lazaric

Research Professor, CNRS, University of Nice-Sophia Antipolis/GREDEG - UMR 7321, France

\section{Edward Elgar}

Cheltenham, UK - Northampton, MA, USA 
PART I

\section{KNOWLEDGE \\ AND ECONOMICS: \\ A HISTORICAL \\ PERSPECTIVE}




\section{What Vilfredo Pareto brought to the economics of knowledge}

\section{Ludovic Ragni}

What economists generally remember about Vilfredo Pareto are his contributions to general equilibrium theory, his definition of optimality and the law that bears his name. Economists refer to Pareto much less as a sociologist. This can be seen as a deficiency to the extent that his sociology actually determines his contributions to the fields of pure and applied economics from a methodological point of view.

Indeed, according to Pareto, economics must answer to the method of "successive approximations". This consists in grasping economic phenomena first inductively, then deductively, so as to be able to offer a mathematically logical explanation, as is done in the experimental sciences. Then the explanation is completed by taking into account whatever the other social sciences have contributed, especially sociology. A synthesis of these differing approaches aims at producing an action theory that would help explain the way economic and social agents think. Pareto sets out to explain how the actors reason either from an individual point of view or from that of social group dynamics.

The reach of his study of this problem can be seen in the theory of logical and non-logical actions developed by the author, especially in his Courses (1896-97). Manucule (1909) and Treatise (1916).' Paretian theory can thus be seen as a reflection on the knowledge economy considered as a field of thought relating to the way agents think, treat, and acquire information and elaborate ways of thinking and belief.'.' It is the result of the interdependence of disciplines as varied as economics, psychology, logic and sociology, to which we would today add the cognitive sciences. Overall the Paretian action theory constitutes a pioneering framework of the "economics of the mind', the importance of which has too often been underestimated.

This chapter aims to revisit this dimension of Pareto's work so as to evaluate its reach in the field of economics. We will show that his works already announce some of his thinking in an effort to try to explain the forms of rationality suitable to economic agents. To do so, we shall assess the epistemological foundations of the hypotheses put forward by Pareto to explain the behavior of economic agents as they set up economic models. Four complementary themes will be touched upon. 
The first will try to show that Paretian action theory, and therefore knowledge, rests on a methodology that implies that economics as a discipline depends upon the other social sciences.

In the second section, we shall indicate that Paretian knowledge theory involves the different concepts of rationality that were systematized later by Simon (Simon, 1976, 1978, 1986, 1990, 1996). Thus we shall show why Pareto's action theory can be interpreted in the light of concepts such as substantive, limited, procedural or even cognitive rationality.

A third stage will lead us to examine how the complex categories that Pareto defines to explain the behaviors of social agents - 'interests', 'derivations', 'residues' and 'elites' - represent the ways by which they acquire knowledge in a complex interactive situation.

We shall end by showing that Pareto's representation of action goes far beyond that which is normally associated with homo aconomicus; in fact, it provides the basis of his analysis of the group dynamics needed to reach equilibrium. We shall illustrate this point by analyzing how Pareto explains the alternative between free trade and protectionism, taking as a starting point the process of 'equilibration' the economic, social and institutional forms knowledge takes.

\subsection{PARETIAN METHODOLOGY AND ACTION THEORY}

Being able to evaluate Paretian action theory in terms of knowledge economics implies understanding its methodological foundations. Shedding light on this method will then allow us to investigate his action theory from the perspective of the forms of rationality that are usually discussed in today's economic analysis.

Pareto's methodology can be described by what he calls the logicoexperimental approach, and applies to both economics and sociology (Pareto, 1981, p. 16). In an effort to grasp social phenomena, the method involves three steps.

The first is inductive: it consists in the observation of behavioral patterns or facts that display some regularities.

The second is deductive: it is concerned with the working out of specific assumptions from which models explaining the laws gathered from previous observations are deduced. These models belong to the fields of economics, sociology and other social sciences. The third step synthesizes the various models so as to reach an overall explanation.

This process is best illustrated by Pareto's analysis of action theory, which consists in the investigation of the way economic and social agents 
act when trying to reach a goal. Pareto's contention is that economics should be concerned especially with logical actions, whereas sociology and psychology should concentrate on non-logical ones. ${ }^{5}$ His Treaty on General Sociology brings these different points of view together.

Pareto's methodology is also characterized by the use of what he calls 'the method of successive approximations'. Regarding action theory, it corresponds to a method that grasps individuals' behavioral patterns and facts from the twofold perspective of subjective and objective knowledge, that is, respectively, from the perspective of how people see and how people produce knowledge when acting.

The first stage consists in observing enough facts in order to 'purify' them. On the basis of these purified elements, scientists can then inductively formulate hypotheses or discover regularities in economic phenomena. They are then able to deduce a theory that can later be confirmed on the basis of these hypotheses or uniformity principles. The suggested models, when dealing with pure economics, are conceived as a first approximation of reality. At this stage, the agents' behavior meets the principles of pure rationality.

During the second stage, the same phenomena are studied in all their complexity, especially allowing for their social, cultural and emotional dimensions. Economic and sociological laws are then considered to be tendentious regularities. At this point, Pareto completes the pure economic or mathematical models by enriching them with input from the other social sciences, thereby making a synthesis of those points of view that should be kept (Freund, 1974; McLure, 2001; Bruni, 2002). This method assumes that the results of pure economics fit in with and depend upon the sociological ones. Logical actions that are confined to pure economics must therefore be made consistent with non-logical actions that concern both economics and sociology (Pareto, 1968, pp. 44, 63). Such a global perspective then enables us to show, for instance, that free trade or protectionism results from both features of pure economics, such as logical actions and pure rationality, and sociological features such as social stratification, illogical actions based on ethical or religious beliefs or bounded or satisficing rationality.

Paretian 'knowledge economics' thus aims at making synthetic models of logical and illogical actions so as to explain the cognitive processes of social actors at work when pursuing a specific aim. Consequently, Pareto's method is first of all both inductive and a priori. It is then deductive to the extent that Pareto seeks to set general laws and tendencies based on observations from which results or forecasts are then deductible. Moreover, Pareto's methodology relates to the logico-experimental method. This method is experimental in the sense that it is based on prior 
observations and is combined with models that are tested on the basis of further observation. It is logical in the sense that it follows the usual scientific procedure, that is, to deduce logically from assumptions the models used to make predictions. Finally, it takes a global ('synthetic') perspective because, by using a series of approximations, it permits us to deal with both economic and sociological models in a unified framework focused on the driving forces of human action.

Pareto's action theory therefore goes much further than the theory of homo aconomicus as described by standard economic theory. It indeed seeks to take into account complex behavioral patterns, explaining them by adopting the complementary angles of homo ceconomicus and homo sociologicus. It is obviously seeking to account for individual rational acts, agents' limited cognitive skills as well as their individual and collective beliefs.

Within this context, logical actions more specifically concern pure economics, be it mathematical or applied, while non-logical actions are the concern of sociology: 'the study of non-logical actions thus belongs mainly to sociology' (Pareto, 1967b, p. 8). It is not, however, always possible to discriminate precisely between those actions that fall within the province of economics and those that concern sociology. The author states in the Manuale that logical actions mainly concern pure economics, whereas in the Treaty he stresses that some economic actions are actually non-logical and some sociological non-logical actions must be taken into account to better explain economic activity.

\subsection{LOGICAL AND NON-LOGICAL ACTIONS AS CONVEYING DIFFERENT KINDS OF KNOWLEDGE}

According to Pareto, for an action to be logical, two conditions must be met. The first is that it must be logical from both the objective scientific point of view and that of the agent carrying it out. Objectivity is thus defined according to current available scientific knowledge, while subjectivity relates to the perception social actors have of the phenomena under consideration.

The second condition implies that, for an action to be logical, both the objective and subjective goals must correspond to each other, or in other words, the means and the reasoning process used to attain the goal must be objectively and subjectively identical.

Obviously, logical actions deal with instrumental and substantive rationality as Simon (1945, 1976, 1978 and 1990) defined it. According 
to this author, appropriate behavior in order to achieve a goal under a known system of constraints is substantively rational. Simon, in his Administrative Behavior (1945), goes so far as to define substantive rationality as all those actions to which the principle of objective rationality can be applied from both the agent's and the scientist's perspectives. How very close the definitions suggested by Simon as related to substantive rationality and those given by Pareto concerning logical actions are thus becomes obvious. More precisely, and to insist even more on the relationship with Pareto, we need to recall that Simon, in his Administrative Behavior, uses the term 'objective rationality' for both the agent and the scientist when speaking about substantive rationality.

In his Manuale, Pareto still specified that 'non-logical action does not mean illogical; a non-logical action may be one which a person could see, after observing the fact and the logic as the best way to adapt the means to the end; but that adaptation has been obtained by a procedure other than that of logical reasoning' (1981, p. 41).

In the Treatise an action is non-logical when 'the objective end differs from the subjective purpose' (Pareto, 1935, p. 78). Pareto distinguishes four kinds (genera) of non-logical actions.

1. There is no logical end, subjectively or objectively.

2. There is a logical end subjectively but not objectively.

3. The end is objectively logical but not subjectively.

4. There is a logical end subjectively and objectively.

Pareto subdivides the third and fourth types (genera) into two sub-types (species): sub-types $3 \alpha$ and $4 \alpha$, which are characterized by the fact that the objective end could be accepted by the subject if he knew it; and sub-types $3 \beta$ and $4 \beta$, where the objective end would be rejected by the subject if he knew it.

Table 2.1 summarizes the typology Pareto developed in his Treatise in 1916.

Pareto's action theory is thus of an intentional nature because it assumes that the individual seeks to reach a goal even if at the outset such a goal is neither totally defined nor conscious (Dennett, 1981, 1987). This concerns mainly the logical and non-logical actions of types 2 and 4 . The intentional nature is less clear regarding the non-logical actions of types 1 and 3.

The non-logical actions of the first and third types indeed assume that the subjects are not seeking a subjective goal. Are they therefore less interesting in economics? They are either precepts or forbidden acts having no explanations for the individual or for science. Type 1, for example, concerns politeness or customary behavior. Type 3 covers principally innate 


\section{Table 2.1 Pareto's typology of actions}

\begin{tabular}{|c|c|c|}
\hline \multirow[t]{2}{*}{ Genera and species } & \multicolumn{2}{|c|}{ Have the actions logical ends and purposes } \\
\hline & Objectively? & Subjectively? \\
\hline \multicolumn{3}{|c|}{ Class I: Logical actions } \\
\hline The objective end an & $\begin{array}{l}\text { Ye subjective p } \\
\text { YES }\end{array}$ & $\begin{array}{l}\text { atical } \\
\text { YES }\end{array}$ \\
\hline \multicolumn{3}{|c|}{ Class II: Non-logical actions } \\
\hline \multicolumn{3}{|c|}{ The objective end differs from the subjective purpose } \\
\hline Genus 1 & NO & No \\
\hline Genus 2 & NO & YES \\
\hline Genus 3 & YES & NO \\
\hline Genus 4 & YES & YES \\
\hline \multicolumn{3}{|c|}{ Species of the genera 3 and 4} \\
\hline $3 \alpha, 4 \alpha$ & \multicolumn{2}{|c|}{$\begin{array}{l}\text { The objective end would be accepted by the subject } \\
\text { if he knew it }\end{array}$} \\
\hline $3 \beta, 4 \beta$ & \multicolumn{2}{|c|}{$\begin{array}{l}\text { The objective end would be rejected by the subject } \\
\text { if he knew it }\end{array}$} \\
\hline
\end{tabular}

acts or reflex behavior. These actions are indeed efficient, often reaching the desired goal without the subject having thought it out or been aware of it.

Type 2 and 4 non-logical actions lead to a discussion of the nature of the means used, that is, to the knowledge and the reasoning processes put into play by individuals to reach an objective. Indeed, if the objective and subjective goals do not correspond, the existence of a subjective aim can help evaluate the type of rationality the subjects used. Rightly or wrongly, the subjects rationalize their actions because human nature has a very conspicuous tendency to put a logical varnish on their conduct (Pareto, 1935, pp. 1120-21).

Logical actions, and non-logical ones, as in types 2 and 4, are carried out because subjects have developed reasons that they consider either as having been well thought out or simply as good. While it seems obvious that logical actions are of the instrumental rationality type, Pareto points out, as concerns the non-logical actions of types 2 and 4 , that they represent 'what the subjects found to be the most appropriate based on their observation of the facts and on logical reasoning, to adapt the means to the end' (Pareto, 1981, p. 41). These non-logical actions can thereby be understood as resulting from an imperfect reasoning mechanism, satisfying the criterion according to which 'the subject has many good reasons 
for believing in such and such a theory $X \ldots$ even though these reasons are logically wrong' (Boudon, 1990, p. 71). In other words, the reasons behind the acts that a subject has can be objectively wrong as they are based on bad reasoning, or unjustifiable beliefs; but they do result from a reasoning process that he considers adequate.

To sum up, Pareto's action theory rests on either objectively good reasons behind logical actions or on reasons that the subjects themselves consider as sufficient, concerning type 2 and 4 non-logical actions.

At this point, it would be useful to discuss what such a behavioral analysis implies in terms of the various forms of rationality economics accepts.

Type 2 non-logical actions relate to acts having a subjective goal without being based on any scientific theory. The subject is incapable of giving a satisfactory rational explanation from a scientific point of view. The objective and subjective goals differ in that the means used cannot reach the desired end. In sociology, these actions concern ritual activities such as those of the 'rainmaker'. According to Pareto, they involve situations wherein the subjects make a mistake but can and do justify their behavior by reasoning, offering explanations that they subjectively judge to be sufficient. This kind of action can admittedly be seen as responding to the principles of cognitive rationality in the sense that it is the historical and social context at the level of scientific knowledge that brings the subjects to justify the means used to reach their ends. Thus, according to Pareto, Greek sailors offered sacrifices to Poseidon to be saved from storms and because they felt they had enough good reasons to do so. The same can be said for those scientists who believed that the earth was flat or refused to believe that Galileo's arguments were good enough to disprove this.

These kinds of action likewise correspond to any number of situations as studied by cognitive psychology within the framework of 'problemsolving analysis' to which Simon dedicated so much of his work. They correspond to the principle of cognitive bias whereby in any number of situations, subjects believe and explain their mistakes by reasoning in the very same way. The reasoning and the knowledge they use are wrong. which leads to non-logical actions. To give an example, many cognitive psychologists (following Simon, 1986) have shown that most subjects give the wrong answers when given tasks where inferential probability reasoning comes into play. They all give the same explanations for their mistakes. In this sense, type 2 non-logical actions correspond to those principles that define limited rationality in its primary sense because the subjects have limited computational capacity making them unable to display satisfactory behavior as seen from an outside, objective knowledge point of view. Cognitive psychologists explain this kind of behavior wherein subjects systematically make the same kinds of mistake and give the same explanation 
for their errors by pointing out the inherent limits to human reasoning powers (George, 1997). ${ }^{6}$

Type 4 non-logical actions cover situations where the economic actor, without mastering any theory or having access to all the information, sets up reasoning processes that he feels, right from the beginning, are all he requires to reach his goal, or not to do so. These illogical reasons are likewise related to the behavior categorized by sociologists as 'fire makers' because the subjects start an activity - more or less efficiently - without having a good idea of all the scientific knowledge underlying it. In this sense, too, the subjects' rationality is limited.

For example, non-logical actions of the $4 \beta$ type are those situations wherein the economic agent would not have started his action if he had known its objective end right from the start. Pareto illustrates this by describing the activity of a producer in an open competition situation.

In the sphere of political economy, certain measures (for example wage-cutting) of businessmen (entrepreneurs) working under conditions of free competition are to some extent non-logical actions of our $4 \beta$ type, that is, the objective end does not coincide with the subjective purpose. On the other hand, if they enjoy a monopoly, the same measures (wage-cutting) become logical actions ... while the businessman aims at reducing costs of production, involuntarily he achieves the further effect of reducing selling prices ... competition always restoring parity between two prices... So competing enterprises get to a point where they had no intention to going. Each of them has been looking strictly to profits and thinking of the consumer only in so far as he can be exploited; but owing to the successive adjustments and readjustments required by competition their combined exertion turns out to the advantage of the consumer. (Pareto, 1935, $\$ 159$, p. 86)

This situation is depicted by the 'pursuit curve' in the Manuale (see Figure 2.1). The curve depicts a situation where a producer at point a maximizes profit on the basis of his understanding of the market - located at $m$ - from the information he has at his disposal at that time. However, when the producer is at $b$, the market has turned into $\mathrm{m}^{\prime}$, leading the entrepreneur to reconsider and make a new set of calculations on the basis of the new information he has received. This mechanism goes on until it reaches position $\mathbf{M}$ where no entrepreneur makes either profits or losses. Situation $\mathbf{M}$ would not have been accepted had the entrepreneur been able to know right from the start of the process that it corresponded to a non-profit situation. Two interpretations of rationality can be given on the basis of this curve.

First of all, one can admit that the actions are non-logical over the long term. During the competitive process, entrepreneurs have no way of knowing that profits and losses will cancel each other out. They would not 


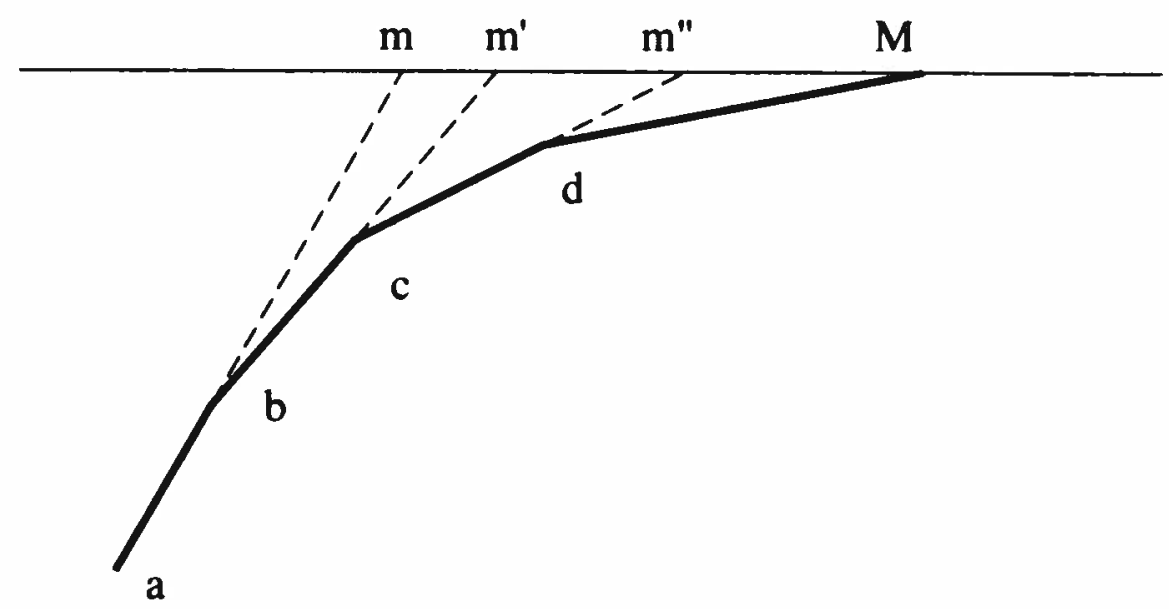

Figure 2.1 Pareto's pursuit curve

have accepted the long-term objective if they had been aware of this, but they do accept the subjective one, which is making short-term profits. The two objectives clearly do not correspond to each other. It is market activity sustained by agents acting through 'trial and error' that brings about short-term profit while canceling it over the long term. This outcome can be seen as limited rationality to the extent that the agents discover their real objective as they adapt to market circumstances given that they are able to obtain enough information to be able to do so. Pareto's analysis illustrates the split that March (1978) points to when he makes the distinction between those rationality models that base behavior on calculated reasoning and those that consider that subjects' behaviors can be explained as a result of a trend largely independent of the choices or calculations of a subject considered as independent. In this case, the example of pure competition that Pareto refers to can be classified among the models of 'systemic rationality'. Paretian entrepreneurs can, at each step of the competitive process, calculate for the best according to the information they have at hand. Yet the results of their calculations, or the objective goal of their acts - to use Pareto's terminology - lies beyond their grasp. This line of reasoning can be put in perspective with Hayek's approach: rationality is systemic because the objective or the results come from adjustments partially due to the system governing the market and the prices at each step of the way and not only from agents' individual behavior. Rationality in this case involves both calculations and systems (Laville, 1998, 2000). Pareto has here demonstrated how impossible it is, whether for an individual or a state, to determine pure competition equilibrium.

Admittedly Pareto sees competition as a real mechanism wherein a series of adjustments takes place, partially beyond the agents' grasp, but 
within a historical time frame. To put it another way, competition cannot be reduced to an atemporal trial-and-error mechanism as Walras suggested, implying that only logical acts must be taken into account. As far as Pareto is concerned, a representation of free competition may allow for logical short-term actions and non-logical long-term ones.

A second interpretation of the 'pursuit curve' can be given. If it is held that substantive rationality deals with situations in which the economic agents are omniscient and therefore capable of reaching the best solutions, it must then also be recognized that reducing production costs in a pure competition situation is a logical action in the short term. On the other hand, this cannot be the case in the long term when agents are unable to know the results of the competitive model (if they did, their actions would be logical). To put it otherwise, not only are the subjects not unaware of the objective goal resulting from the competitive marketing process that their activities spontaneously bring about, but their subjective goal of price reduction does not fit in with the objective one, that is, the fact that the theoretical result of the competitive process implies long-term zero profits. In the short term and throughout the competitive process, they are nevertheless able to make sophisticated calculations in an effort to adapt, as shown in the pursuit curve: 'Economic questions bring up questions analogous to those studied in mathematics under the name pursuit curve' (Pareto, 1964, \$41, t.1). This quotation suggests that Pareto is concerned about how agents adapt and how they correct their mistakes step by step. Figure 2.1 corresponds exactly to that of a differential equation solved by the tangential method, which Pareto, being the good mathematician that he was, could not have known well. The implications of the situation as it is described is therefore that the producers can themselves make these calculations and that at each step of the process, they have access to the available information ex ante, thus conforming to the principles of substantial rationality. Although their actions and expectations can be correctly described by the model of substantive rationality, they are not to be held as logical actions. Taken as a whole, that is, in both the short and long terms, Pareto's example implies that the economic subject has extensive calculating abilities but faces an environment that is so complex that he can neither know nor control it totally and perfectly.

From what has been discussed so far, it seems that Pareto's action theory involves the articulation of different kinds or models of rationality. As we shall try to show, Pareto's approach is an attempt to provide a coherent overall explanation of how different types of models of rationality interfere in the building of knowledge. To a certain extent, Pareto's action theory can be seen as an explanation of how subjects acquire knowledge. In an attempt to bring together economics and sociology, Pareto tries to 
show how dynamic economic and social processes of equilibrium organize and determine each other. Within this interactive process, specific categories are involved. We shall now discuss the nature of these categories and the ways in which they work together in structuring the actors' knowledge.

\subsection{ACTION THEORY AND PARETO'S CATEGORIES IN THE BUILDING OF KNOWLEDGE}

The forms of thought and cognition that underlie Pareto's action theory can be grasped from the perspective of two complementary approaches. The first interpretation is 'cognitivist'; the second 'emotionalist' (Bouvier, 1999c). On the one hand, Paretian action theory can be seen as cognitivist in that it postulates that subjects act according to objective reasons or on the basis of those they consider good. These reasons come from a process of conscious objectification. The cognitivist interpretation assumes that agents determine their choices on the basis of mental activities that they set into play in order to transform information into knowledge that they can then better use to achieve their purposes or to adopt the proper behavior. The 'emotionalist' interpretation, on the other hand, insists on the fact that subjects are guided by their passions and feelings. It places much more emphasis on the unconscious mechanisms that cannot be controlled by reason.

The categories 'residues', 'derivations', 'interests' and the 'elites or heterogeneity of society', which Pareto refers to when describing the evolution of economic and social equilibrium, provide many examples of both the 'cognitivist' and 'emotionalist' interpretations.

Studying how these categories underlie logical and non-logical actions can help to better understand how Pareto conceives the process of knowledge acquisition by subjects. According to him, agents, as they make more and more contacts, acquire knowledge that they will then use and manipulate, often in an opportunistic fashion, when trying to reach a goal that was not clearly defined at the outset. Therefore Paretian action theory also corresponds to a theory of knowledge building which, as we shall discuss, can be placed within the theory of procedural rationality.

In order to provide a better understanding of the connections between Pareto's knowledge theory, action theory and types of rationality, we propose to revisit the four categories the author refers to, as given above.

The 'residues' are a manifestation of feelings, emotions and human instincts. They are the mirrors of the psychological state of individuals. Though unconscious, they provide individuals with ready-made logical paths to follow. According to Busino (1967, 1999), their composition 
comes from a spontaneous, balanced, and self-regulated ${ }^{7}$ organization of mental processes expressed by logical and non-logical actions.

The logical part of the residues is made up of a series of spontaneous cognitive functions. For example, identification, representation, naming, classification and serializing are some of the functions that can be found. Taken this way, the residues strengthen the idea that Pareto developed a cognitivist model. Yet residues are not objective entities that can be observed in themselves. Only their effects can be observed, thus giving certain validity to the interpretation of Pareto as an emotionalist in the sense that some of the residues may be unconscious. This being the case, admittedly Pareto's explanation of action and reflection partially rests on a kind of black box made up of residues that can only be observed when they manifest themselves. On the other hand, a cognitivist interpretation of action assumes that an act comes from reason itself even if the subjects can make mistakes or believe in something for the wrong reasons. They can always be rationalized or defended from an epistemological point of view. This is typically the case for type 2 and 4 non-logical actions. The emotionalist interpretation, however, gives plenty of room to the passionate determinants of actions found especially in type 3 and 4 non-logical actions.

Likewise, residues are the very source of that share of the constant forces that lead men to act individually or collectively. Among the six classes of residues that Pareto describes, two are particularly interesting to economists. They are, on the one hand, the 'instinct for combination' residues that concern all those arrangements aiming at putting knowledge or beliefs together in order to innovate. On the other hand, they are the 'persistence of aggregate' residues that allow social actors to formulate the arguments they need to justify an ideology or a certain number of historical institutions. The persistence of aggregate residues thus corresponds to all the reasons put forward to resist those changes and innovations that will give an advantage to certain social classes.

'Derivations' come from conscious and intentional activities, that is, logical and non-logical reasoning. They deal with all those actions started by the subject or a group of subjects to convince others without the latter being always considered as scientifically accurate. ${ }^{8}$ In some cases, the reasoning is valid (logical actions); in others, they are partially wrong (nonlogical actions.)

Concerning derivations, Pareto indicates that even though 'men are led by their feelings, passions and interests; they like to think that they only follow their reason' (Pareto. 1967b, p. 9). Derivations allow us to develop explanations and give the explanations that everyone will agree to whether or not the subjects believe them or they do not appear to be logical. Derivations correspond to 'pre-constructed' elements that both underlie knowledge and 
are knowledge known as common sense aiming at producing social rules or norms, and are the conditions required to structure symbolic meaning. In this sense, they can be considered as routines. They aim at establishing social rules, norms or the conditions needed to structure symbolic meaning. Their function is to put together deductive and inductive acts that may be logical or pseudo-logical. Obviously, they are particularly relevant for a cognitivist interpretation of Paretian action theory. They concern valid or invalid inferences as well as whatever the subjects consider to be the best in justifying or self-justifying their acts and theories, or in convincing others. In the latter case, derivations might lend support to a logical argument that might turn out to be purely strategic or the result of deliberation. The latter are then carried out through interactions of different agents tending towards an identical objective that they gradually understand through the interactivity itself. De facto, derivations belong to the area of limited rationality and situated cognition. It can be admitted that derivations produce knowledge in an environment where the agents are interacting and that they then understand during the discussions leading them to make decisions. Thus, for Pareto, action is not so much the result of rigid deduction as it is a process of coordination between groups of agents with often conflicting interests. Subjects can improve the ways they reach their goals by interacting (situated cognition) and by using their environment (situated action). Derivations are thus concerned with interactive or strategic rationalities in so far as Pareto uses them for describing how certain groups of subjects fight with others to impose upon them this or that reason or goal.

Indeed, according to Pareto, a great number of economic and social situations involve groups of subjects with antagonistic interests, which use derivations to convince others that their opinion is the right one. From this perspective, derivations could be understood as beliefs, which takes place alongside valid syllogistic reasoning, and are utilized in designing strategic behavior. The kind of rationality they thereby support is likewise argumentative as well as being limited. In fact, most of the examples Pareto gives do not distinguish the means used to attain a goal, that is, the arguments and heuristic models that support his arguments about derivations as is the case for those models based on the hypothesis of substantive rationality.

'Interests' are defined as all those economic and social desires aimed at obtaining possession of economic goods (Pareto, 1968, pp. 3 and 1406). Interests correspond to all those elements that push individuals to act in order to obtain those goods that they find useful. Both interests and residues are often described as belonging to the broader instinct category. Pareto does his best not to identify interests with residues, unlike many of his commentators. Interests are indeed objectified elements because they deal with material goods that can be subjectively assessed in terms of 
economic satisfaction, while residues are based on mental activities whose object is not perfectly defined by the individual:

Interest. Individuals and communities are spurred by instinct and reason to acquire possession of material goods that are useful - or merely pleasurable - for purpose of living, as well as to seek consideration and honors. Such impulses, which may be called 'interest', play on the whole a very important part in determining the social equilibrium. (Pareto, 1935, p. 1406)

The 'elites' or 'heterogeneity of society and circulation' correspond to categories of individuals defined according to the qualities they possess. More precisely, Pareto uses a rating for each individual so as to measure his qualities at a given time or for a specific activity. Pareto comes to see it as a fighting process to obtain power or to defend an ideology or an institution (Pareto, 1968, pp. 2025-57). Social change involves the replacement of the elite, which is very often associated with a renewal of the economic institutions or the laws that organize power. In this case, social change emerges from a struggle between elites generally, belonging to two different leadership groups. They are characterized by differing interests, derivations and residues. Social equilibrium can then be defined as a set of rules brought about by the 'circulation of the elite' who have the ability to build logical and non-logical arguments by using derivations to impose their interests. Hence, for Pareto, the distribution of wealth and the efficiency of the various forms of economic actions are the reflection, on average, of individual qualities. The more capable individuals benefit from the best resources because they know how to impose their version of political, institutional and economic actions on others.

The choice between free trade and protectionism, which Pareto discusses at length in the Manual and the Treatise, provides a good example of this kind of social dynamics. As we shall show in the following section, this example also permits us to investigate the dynamics of social change from the perspective of the cognitive mechanisms and the forms of knowledge they involve.

\subsection{PARETO'S KNOWLEDGE ECONOMICS AND SOCIOLOGY: THE FREE TRADE/ PROTECTIONISM CHOICE}

In the Manual as well as in the Treatise, the choice between free trade and protectionism is based on the articulation between residues and derivations on the one hand, and between logical and non-logical actions or reasoning on the other. 
Pareto sees protectionism as the result of antagonistic relationships among the socially best organized and most convincing subjects able to make their opinions win the day even if they are false from the point of view of mathematical economics. Pareto's analysis points out how certain political coalitions or interest groups aim at influencing institutions or laws to lean either towards protectionism or free trade in line with their own interests:

The major reasons why coalitions succeed are the direct or indirect help provided by the law; in other words, it is because the public powers exercise pressure on their behalf that they succeed. (Pareto, 1964, p. 253)

Pareto emphasizes the practices, rational procedures and strategies that bring interest groups to defend their opinions even if the latter go against the common welfare, as envisaged from the perspective of pure economic theory, that is, on the basis of the mathematical demonstration of the superiority of free trade over protectionism. What Pareto shows is that this theoretical superiority is not necessarily confirmed by facts and effective individual or group behavior, but is context dependent: free trade, just like protectionism, comes from a process of knowledge that instigates both logical and non-logical actions manifested by the categories, that is, residues, derivations, interests and the elites.

Thus Pareto is in favor of free trade because the mathematical demonstrations prove it to be superior in terms of social welfare. However, according to the logico-experimental method, he tries to explain why protectionism so often imposes itself as the result of interactions of logical and non-logical actions or as the outcome of interest group struggles.

Pareto distinguishes two types of situation in the Manual and in the Treatise. First, there are those wherein certain protectionist or free trade actions benefit every member of a society; second, those wherein these actions put some members at a distinct disadvantage. There may be an infinite number of possibilities, but protectionism always favors one class over another. Pareto hereby stresses the dynamic nature of the social elite, and puts aside the weight of the mathematical demonstrations of the superiority of free trade, and consequently, of objective knowledge or logical action.

Even if we were to demonstrate beyond any doubt that protectionism always leads to the destruction of wealth; even if this had been taught to every citizen in the same way as we teach the alphabet, protectionism would lose so few proponents and free trade would gain so few that the effect can almost be put aside. even completely so. (Pareto, 1981, p. 520) 
The four major reasons that explain why protectionism survives are to be found in the logical and non-logical action theory or in the strategies reasoning comes up with to maintain international trade.

First, some subjects, such as persons of independent means, have a vested interest in defending protectionism in order to increase their own welfare (means of livelihood). Their actions are subjectively logical even though they do not correspond to the objective logic of science, which shows that protectionism is harmful to the community. Second, Pareto reminds us that many politicians defend protectionism to bring in more public revenues. Once again the subjective and objective goals do not correspond. Third, Pareto points out that nationalists are traditionally and ideologically in favor of protectionism. This belief comes from axiological rationality, as defined by Boudon (1997), and is therefore illogical in Pareto's eyes.

Protectionism is generally set up by a league whose most important members are ... those so convinced of their nationalist feelings as to make them believe that protectionism serves to defend the motherland against foreigners . . . they imagine or pretend to believe that these measures are in tune with their ethics. They are a special breed (nationalist partisans); when of good faith, one can show them the moon in a well; when of bad faith, they show it to others. (Pareto, 1981. p. 521)

This passage refers to good faith as supporting axiological beliefs and to the fact that social groups acting out of hypocrisy will readily develop pseudo-logical reasons to justify reaching their goals. Fourth and lastly, Pareto points to those who, even when they have the intellectual faculties but are lacking in courage, will choose actions based on derivations to defend their interests.

Pareto's analysis of the choice between free trade and protectionism depends on an overall perspective and the successive approximation method in an attempt to bring together the economic theory viewpoint (on the basis of logical actions and objective knowledge) and the sociological one (on the basis of non-logical actions and subjective knowledge). What indeed requires explanation is how individuals cognitively define and justify their actions to promote either one of these two theories of international trade. Pareto's analysis is based on a dialectical process between economic theoretical knowledge and sociological knowledge, be it individual or collective, subjective or objective. In his Treatise, Pareto illustrates the choice between free trade and protectionism by means of a chart (Figure 2.2), which shows how the different types of actions are ordered in relation to the categories underlying them. 
- The $\mathrm{C}$ element is either free

trade theory or protectionism.

- The $\mathrm{C}$ element is at the root of the mathematical demonstration of free trade's superiority.

- Knowledge comes from logical actions if free trade wins.

- Knowledge, in this case, is objective.

- If free trade is not set up, the $C$ element is the root of protectionism.

- In this case. protectionism comes from reasoning backed up by derivations.

- Actions are likewise in this case non-logical.
- The B element results mainly from collective or individual actions and subjective knowledge.

- To a lesser extent, it is the result of collective or individual actions and objective knowledge born from the A, C and D elements.

- C represents all concrete acts within free trade or protectionism.

- Actions are logical but mostly illogical.

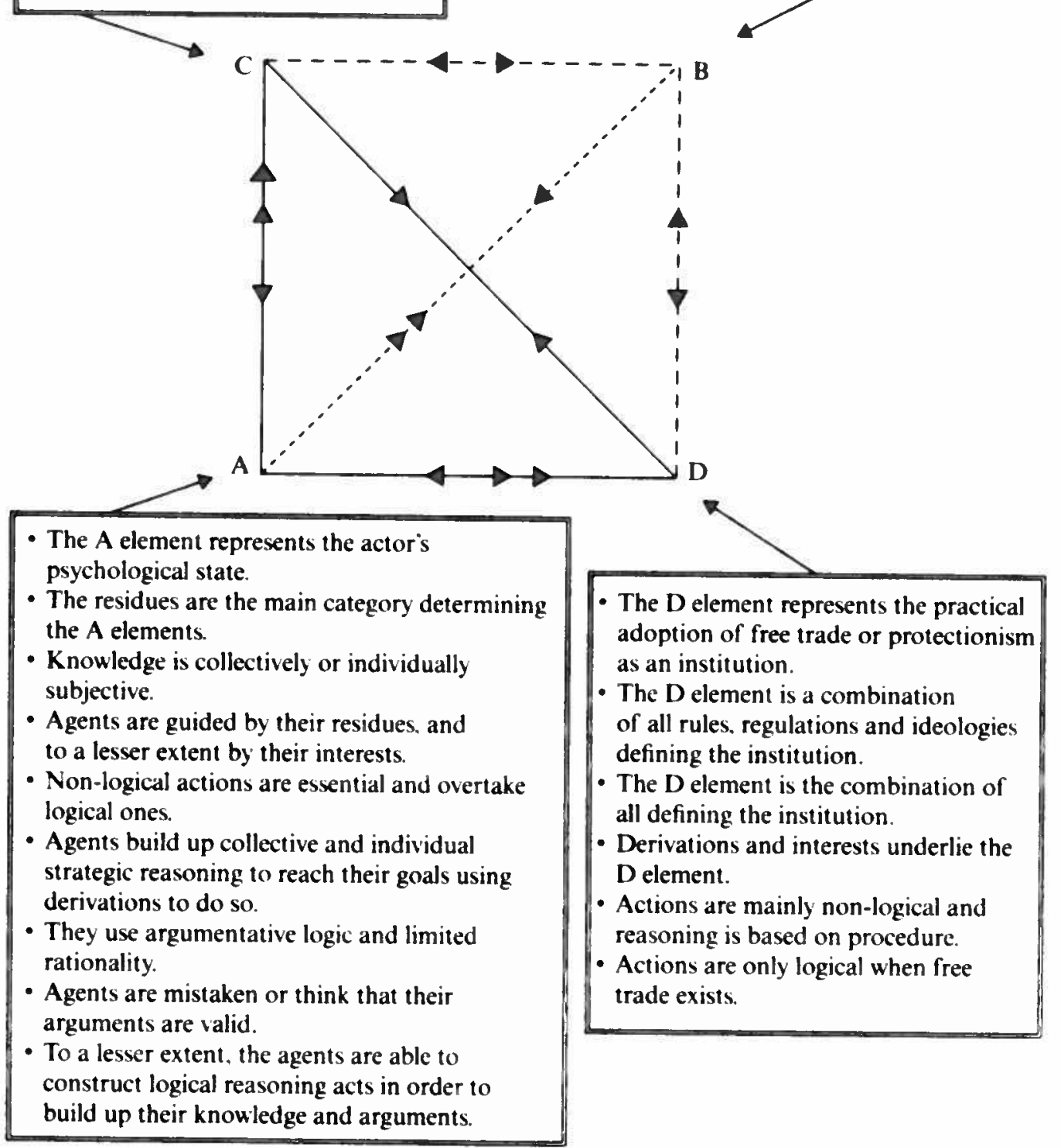

\section{Figure 2.2 Actions ordered by underlying categories}


Four elements designated by the letters A, B, C and D are set up as a square. They each contain varying degrees of logical and non-logical actions. They are also made up of varying degrees of residues, interests, derivations and heterogeneity of society or elites. The elements A, B, C and $\mathrm{D}$ are connected to each other according to three major relationships and three minor ones. The latter are shown as dotted lines; the former as solid lines. Single-headed arrows show the direction of the minor relationships, and double-headed arrows those Pareto considers as highly intense (Pareto, 1968, \$167).

We have added to the author's original chart the categories that are most involved in the elements A, B, C and D to make it easier to see how logical and non-logical actions interact in a way which is more favorable to either free trade or protectionism. The squares indicate what kind of knowledge is mobilized so that either type of international trade takes place.

In order to understand the arguments behind the various relationships, we need to make a few comments about what lies behind the letters A, B, $\mathrm{C}$ and $\mathrm{D}$.

Element A represents the psychological states of the subjects resulting from economic, political and social interests that organize their social lives. It is essentially the residues, where non-logical actions take shape. It is also where, to a lesser extent, certain logical actions may be used to define or justify (either rightly or wrongly, but always for good reasons) free trade or protectionism theories.

By element D Pareto designates those factors that favor the adoption of a theory, an ideology, or a religious or philosophical morality. In this case, both residues and interests underlie this item. Interests act as all the factors expressing the subjects' desires for wealth. Hence the letter D corresponds to the legal rules and the institutions that are associated with free trade or protectionism. It is the result of clashes between interest groups or any other elite category capable of making the legal rules and the institutions go in their favor. Pareto gives many clear examples from history to show how this or that interest group was able to bend the laws which at times govern free trade and at others protectionism.

Element $\mathrm{C}$ contains the mathematical theory behind either free trade or protectionism. These theories not only belong to the domain of logical actions, but also derive from interests and residues whenever the latter are not a logical cover-up but actually do underlie valid logical reasoning. Knowledge is objective whenever free trade predominates because it is based on a mathematical demonstration where only logical actions are at work. On the other hand, if protectionism predominates, it is the result of non-logical actions that satisfy some who, guided by their interests or 
false beliefs, have successfully imposed their point of view through either sufficiently reasonable arguments or slyness.

Non-logical actions are really out of the question when pure economic theory is being dealt with, but are, on the other hand, at the very heart of the changes in theory whenever the fact of abandoning free trade in favor of protectionism requires justification. In this case, residues are rationalized through the derivations, whose function is to give a logical varnish to the arguments put forward by the interest group to enable it to impose its point of view on the lawmaker in the pursuit of its own advantage, pushing the latter to adopt either free trade or protectionism.

Pareto thinks that logical actions predominate when a theory is being formulated and when it comes to finding ways to impose it on others. The category interests, made tangible through the use of indifference curves and logical demonstrations, then plays the main role. In this sense, it is seen as all the 'reasoned or instinctive tendencies' (Pareto, 1968, \$2211) that come into play when formulating a theory.

On the other hand, in every complex situation where there are divergent interests or groups acting strategically, non-logical actions come to the forefront. Here derivations play the lead role. This category underpins the ruses and reasons that a subject, or a group, can set up to convince others that the international trade theory he defends is the best one even if it turns out to be suboptimal in the Paretian sense. In most of the situations Pareto describes, social dynamics is based on the meeting of the derivations category and that of social heterogeneity. This meeting also concerns interests, but to a lesser degree. The elite in favor of protectionism oppose those in favor of free trade within this framework. This is indeed a struggle between the strongest and the weakest that in no way assumes that a logical scientific demonstration might lead a particular category of elite to emerge. Protectionism, seen as the result of a battle among the elite, is an objective that would not have been accepted had the social actors seen that their actions would lead to a worse situation than under free trade (type $4 \alpha$ non-logical action).

Pareto's endeavor is to explain the facts as shown from daily experience. He therefore sets out to explain why protectionism has often triumphed throughout history. The argument relies on the relative weight of nonlogical actions and the related influence of residues and derivations at work in the interest game played by the different entities fighting to attain their goal.

For example, as far as the elite in favor of protectionism is concerned, Pareto emphasizes that whenever it is being questioned, its members are moved by second-class residues known as the 'persistence of aggregates'. The residues will then be described as increasingly inefficient routines. 
Those members of the elite in favor of free trade will be pushed to act by the first-class residues - 'instinct of combinations', such as political innovation combined with opportunism or lobbying, and efficiency. The elite in favor of protectionism and the elite in favor of free trade will come up with both pseudo-logical and logical reasons to justify their respective positions. Going from protectionism theory to that of free trade happens whenever the second type of residues win the day.

Finally, element B corresponds to the concrete manifestations, in action, of the psychological states described in elements $A, C$ or $D$. Concerning free trade or protectionism, B synthesizes the effective economic actions of agents involved in real international trade relations. What was said about $D$ also applies to $B$. In other words, actual exchanges themselves have more influence on the rules and institutions than the free trade mathematical theory. Yet $D$ relies directly on $A$ and indirectly on $B$, so that once again the residues - and to a lesser extent the interests and derivations - come together to modify the economic agents' actions, leading to new international trade regulations over time. It is clearly the residues, non-logical actions, supported by the elite with superior qualities that influences social dynamics, bringing about the appearance of a certain equilibrium over time. Logical actions are only used by some of the elite to help them improve their situation.

For example, $C$ is the theory of free trade; $D$, the concrete adoption of free trade by country; A, a psychic state that is in great part the product of individual interests, economic, political and social, and of the circumstances under which people live. Direct directions between $C$ and $D$ are generally very tenuous. To work upon $C$ in order to modify $D$ leads to insignificant results. But any modification in A may react upon $C$ and $D$. D and $C$ will be seen to change simultaneously, and a superficial observer may think that $D$ has changed because $C$ has changed, whereas closer examination will reveal that $D$ and $C$ are not directly correlated, but depend both upon a common cause, A. (Pareto, 1935, p. 91)

Once again, residues and non-logical actions play the main role in adopting free trade (element B) or in setting up the rules that organize it (element $D$ ), while the perfect rational theory about free trade appears as secondary (element $\mathrm{C}$ ). This is so true that understanding how social actions organize themselves as a result of the interdependence of the residues raises the problem of how to accede to knowledge, a hurdle Pareto finds it difficult to jump. Element $\mathrm{A}$ can only be perfectly known by studying psychology. Only the logical and the non-logical justifications in element $C$ and the concrete actions of international trade placed in element B come to light:

But $C$ and $D$ are simply consequences of a certain psychic state, $A$. There is nothing therefore to require perfect logical correspondence between them. We 
shall always be in the wrong, accordingly, when we imagine that we can infer B from $C$ by establishing that correspondence logically. We are obliged, rather, to start with $C$ and determine $A$, and then find a way to infer $B$ from $A$. In doing that, very serious difficulties are encountered; and unfortunately they have to be overcome before we can hope to attain scientific knowledge of social phenomena. (Pareto, 1935, p. 92)

Using Simon's perspective, we may, in the light of the example of the choice between free trade and protectionism, summarize Pareto's action theory and his related conception of knowledge as follows.

First, rational behavior cannot be conceived without taking into account the mental deliberative process that precedes choice. This behavior can be linked to the satisfacing principle as defined by Simon.

Second, the subjects' behavior can be considered appropriate to the subjective aim sought (objective in the case of logical actions) even if it is the result of an imperfect reasoning process. The latter is described as a deliberative mechanism preceding the selection of the action. It is founded on logical reasoning (perfect or imperfect), as can be seen in the derivations. It is likewise based on pseudo-logical reasoning under the influence of the residues. The reasoning and deliberating acts are carried out in situ so that the rationality Pareto gives the subjects implies that they can use their environment to improve their reasoning, actions or the strategies set up to reach their goals. More often than not, these activities are strategic due to the fact that they are the result of struggles between opposing groups with conflicting interests.

Third, Pareto's action theory not only takes into account reasoning processes but also the process that generates the subjective representation of the choices to be made. This process is both cognitive and sociologically situated, for it not only depends on having thought things through using intuitive mechanisms but also on identification to the particular group or set of values that the world's complexity brings out. The latter gives rise to axiological reasoning processes. ${ }^{9}$

\subsection{CONCLUSION}

What has been developed above highlights to what degree Pareto's economics depends on and is contained in his sociology. Notwithstanding that the two disciplines are still separate, Pareto's action theory continues to structure all of the social sciences (including more specifically economic sociology) and remains the first general attempt at understanding how economic subjects reason, rationalize their decisions, and acquire or use knowledge. 
Our argument led us to put Pareto's typology of action (logical and nonlogical actions) and conception of rationality in perspective with more recent approaches as varied as those of Simon or Boudon. Setting this perspective has allowed us to explain how the kinds of knowledge mobilized by economic subjects in order to reach a goal are organized when economists seek to take complex social relationships into account. Far from reducing Pareto's rationality theory to a substantive concept such as can be found in his construction of general equilibrium, his sociological categories help design a knowledge theory wherein cognitive rationalization activities are naturally limited, intentional, procedural, situated, strategic and possibly axiological. Pareto's endeavor was to construct a logico-experimental theory of logical action and knowledge that aims at demonstrating how social equilibrium emerges and evolves. It is also an action theory where homo rationalis meets homo aconomicus, homo sociologicus and homo ethicus. Although these two aspects are often left behind in economic theory, there are however grounds for comparing Pareto with Hayek's later work as developed in particular in his famous 1937 article 'Economics and knowledge'. Hayek's contention is indeed that it is not possible for economists to analyze social processes on the basis only of a priori hypotheses or pure individual choices. Putting aside the assumption of perfect rationality implicitly means placing Pareto's logical action theory in the background.

In the same text, Hayek sets the problem of the epistemological status of those hypotheses that guarantee the general equilibrium theory so that he can better point out how they fail to take into account interactions taking place among social actors. From this perspective, it is possible to establish a parallel between Hayek's conception of knowledge and Pareto's typology of action, but a precise account of those possible connections is beyond the scope of this contribution.

\section{NOTES}

1. The expression 'non-logical action' is to be found for the first time in a letter to Panteloni dated 17 May 1897 (Bobbio, 1961 and 1964).

2. Regarding this, Pareto's Treaty of General Sociology was translated into English as Mind and Society: A Treatise on General Sociology. It is the first of a long list of studies on the sociology of knowledge from a great variety of different authors, from Perrin (1966), Berger (1967), Aron (1967), Freund (1974), Maniscalco (1994), Gislain and Steiner (1995), Passeron (1995), Bouvier (1999a, 1999b) or Boudon (1990, 1998a, 1998b, 1998c, 2000). In a complementary way, economists have paid particular attention to the border that Paretian action theory introduced between economics and sociology (Steiner. 1995, 1998, 1999; Legris and Ragni, 1999, 2004, 2005: Bruni and Guala, 2001) by putting it within the framework of knowledge economics. 
3. This aspect of Pareto's work continues to determine how the various social sciences are structured (Boudon, 1999a).

4. Cf. Rizzello (1997) on this theme.

5. The logical-experimental method applies to economics and sociology the methods used by nineteenth-century physicists and engineers. This has often led to Pareto's being considered as belonging to the classical inductivist school of thought (Marchionatti and Gambino, 1997; Marchionatti, 1999; McLure, 2001: Bruni. 2002). This opinion should be seen somewhat differently to the extent that Pareto uses examples or observations (Aron, 1967) rather than the experimental method in its strictest sense simply because it is seldom possible, in either economics or sociology, to make repeated and codified experiments. Pareto uses a great many examples taken from history as the source of his hypotheses and as ways of confirming the models developed using the inductive method.

6. It is quite difficult to quote all the authors or schools of psychology that use the cognitivist paradigm when treating problem solution. Still, the works of Wason (1969). Wason and Johnson-Laird (1969, 1971), Wason and Golding (1974) and George (1997) concerning conditional reasoning are based on modus ponens or modus tollens, which assume that agents' errors have at least four sources. First. error comes from the general atmosphere or the context wherein the test is being administered (Woodworth and Sells. 1935: Wetherick and Gilhooly. 1990). Second, error comes from a more or less abstract formulation of the problem. Third, error depends on how familiar the subject is with the task being tested (Chen and Holyoak, 1985; Didierjean and Cauzinille-Marmèche, 1997). Fourth, it depends on the mental models the subject has built for himself in an effort to solve problems. These mirror his limited cognitive abilities when he attempts to come up with an adequate representation of the problem he faces (Jonson-Lair and Byrne, 1991; Bara et al., 1995).

7. This obviously bears on F. von Hayek's work in psychology as found in The Sensory Order: An Inquiry into the Foundations of Theoretical Psychology (1952) and in his commentaries on the way Pareto looks at rationality in Scientism and the Social Sciences.

8. Most authors (Monnerot, 1978; Busino, 1999) would agree that non-logical actions are mostly guided by the feelings category and especially by the residues that leave greater room for the 'pulsional' magma than to the logical or pseudo-logical reasons an individual could give. In this case. Pareto's explanation of the causes behind an act would belong to the 'hot theories' group in sociology.

9. 'As creatures of bounded rationality, incapable of dealing with the world in all of its complexity, we form a simplified picture of the world, viewing it from our particular organizational vantage point and our organization's interests and goals' (Simon, 1996. p. 43).

\section{REFERENCES}

Aron, R. (1967), Les étapes de la pensée sociologique, Paris: Tel - Gallimard.

Bara. B.G., Bucciarelli, M. and Johnson, L.P.N. (1995), 'Development of syllogistic reasoning'. American Journal of Research, 63, 69-93.

Berger, B. (1967), 'Vilfredo Pareto and the sociology of knowledge', Social Research. 34 (2).

Bobbio. N. (1961). 'Vilfredo Pareto's sociology in his letter to Maffeo Pantaleoni', Banca Nazionale del Lavoro Quarterly Review, 14 (58), 269-316.

Bobbio, N. (1964), 'Introduction to Pareto's sociology'. Banca Nazionale del Lavoro Quarterly Review', 17 (69). 180-96.

Boudon, R. (1990), L'Art de se persuader des idéc's douteuses, fragiles ou fausses. Paris: Fayard. 
Boudon. R. (1997), 'L'explication cognitiviste des croyances collectives', in R. Boudon, A. Bouvier and F. Chazel (eds). Cognition et sciences sociales, Paris: PUF, pp. 19-54.

Boudon, R. (1998a), Erudes sur les sociologues classiques, tome I, Paris: PUF.

Boudon, R. (1998b), 'Le phénomène idéologique: en marge dune lecture de Pareto', in Boudon (1998a).

Boudon, R. (1998c), "Au-delà du "modèle du choix rational", in Saint-Sermin et al. (1998).

Boudon, R. (1999a), 'L'actualité de la distinction parétienne entre actions logiques et actions non logiques', in R. Bouvier (ed.), Pareto aujourd'hui, Paris: PUF, pp. 35-70.

Boudon. R. (1999b). Le sens des valeurs, Paris: Quadrige/PUF.

Boudon, R. (2000). Etudes sur les sociologues classiques, tome II, Paris: PUF.

Bouvier, A. (1999a), Pareto aujourd'hui, Paris: PUF.

Bouvier, A. (1999b), Naturalisme et actionnisme chez Pareto. Pertinence des problèmes parétiens en sociologie cognitive', in A. Bouvier (ed.). Pareto aujourd'hui, Paris: PUF, pp. 273-92.

Bouvier, A. (1999c), 'La théorie de l'équilibre social chez Pareto: une théorie paralléliste. Versant causal et versant intentional de l'équilibre social', Revue Européenne des sciencés sociales, XXXVII (1 16), 245-54.

Bruni, L. (2002), Vilfredo Pareto and the Birth of Modern Microeconomics, Cheltenham, UK and Northampton, MA. USA: Edward Elgar.

Bruni, L. and Guala, F. (2001). 'Vilfredo Pareto and the epistemological foundations of choice theory', History of Political Economy, 33 (1), $21-48$.

Busino, G. (1967), 'Introduction à une histoire de la sociologie de Pareto', Cuhier Vilfredo Pareto. Vol. XII, Genève: Droz.

Busino, G. (1999), 'L'actualité des travaux de Pareto', Revue Européenne des Sciences Sociales, XXXVII (116), 359-80.

Chen, P.W and Holyoak, K.J. (1985), 'Pragmatic reasoning schemas', Cognitive Psychology, 17 (4), 391-416.

Dennett, D. (1981). 'Three kinds of intentional psychology', in R. Healey (ed.), Reduction. Time, and Reality, Cambridge: Cambridge University Press, pp. 37-62.

Dennett, D. (1987). The Intentional Stance, Cambridge. MA: MIT Press.

Didierjean, A. and Cauzinille-Marmèche, E. (1997), 'Eliciting self-explanations improves problem solving: what processes are involved?', Current Psychology of Cognition, 16, 235-351.

Freund, J. (1974), Pareto: la théorie de l'équilibre, Paris: Seghers.

George, C. (1997), Polymorphisme du raisonnement humain. Paris: PUF.

Gislain, J.-J. and Steiner, P. (1995), La sociologie économique 1890-1920. Paris: PUF.

Hayek, F. (1952), The Sensory Order: An Inquiry into the Foundations of Theoretical Psychology. Chicago, IL: Lniversity of Chicago Press.

Hayek, F. (1983). Scientisme et sciences sociales, Paris: PLF.

Jonson-Lair, P.N. and Byrne, R.M.J. (1991), Deduction. Hove, UK: Lawrence Erlbaum.

Laville, F. (1998). 'Modélisation de la rationalité: de quels outils dispose-t-on?', Revue Economique, 49 (2), 33565.

Laville, F. (2000), 'La cognition située. Une nouvelle approche de la rationalité limitée', Revue Economique. 1301-40.

Legris, A. and Ragni, L. (1999), 'Recouvrement du champ de l'économie dans l'(euvre de Vilfredo Pareto', Revue européenne des Sciences sociales. XXXVII (116), 325-46.

Legris, A. and Ragni, L. (2004), 'La représentation de la rationalité des acteurs dans l'ouvre de Pareto: une tentative de mise en ordre', Revue d'écomomie politique, 371-92.

Legris, A. and Ragni, L. (2005). 'Théorie de l'action, rationalité et conception de l'individu chez Pareto'. Cahiers d'Economie Politique, No. 49, 10326.

McLure, M. (2001), Pareto, Economics and Society: The mechanical analogy. London: Routledge.

Maniscalco, M. (1994), La Sociologia de Vilfredo Pareto e il Senso della Modernità, Milano: Franco Angeli. 
March. J.G. (1978), 'Boundary rationality, ambiguity, and the engineering of choice'. Bell Journal of Economics, 9, 587-608.

Marchionatti, R. and Gambino, E. (1997). 'Pareto and political economy as a science: methodological revolution and analytical advances in economic theory in the $1890 \mathrm{~s}^{\circ}$, Journal of Political Economy, 105 (6), 1322-48.

Marchionatti, R. (1999). 'The methodological foundation of pure and applied economics in Pareto'. Revuc européenne des Sciences sociales, XXXVII (116), 277-94.

Monnerot, J. (1978). 'Pareto-Freud ou l'introduction à la doxanalyse'. in Intelligence et politique, 2 tomes. Paris: Gauthier-Villars.

Pareto. V. (1896 97/1964). Cours d'économie politique', Genève: Droz.

Pareto. V. (1909/1981), Manuel d'économic politique, Genève: Droz. First Italian edn Manuale di Economia Politica con una Introduzione alla Scicn=a Sociale. Milan: Societa Editrice Libraria.

Pareto, V. (1916/1968), Traití de' Sociologic Générale, Genève: Droz.

Pareto. V. (1935). The Mind and Sociolog!. (Traité de Sociologie Générale). Harcourt. Brace Einaudi editore.

Pareto. V. (1966a), Marxisme et économie pure, Genève: Droz.

Pareto, V. (1966b), Mythes et Idéologies. Textes réunis par G. Busino, in Oeurres complites, tome VI, Genève: Droz.

Pareto. V. (1967a), 'Lettres d'Italie', in Oeuvres complètes, tome X, Genève: Droz.

Pareto, V. (1967b), 'Sommaire du Cours de sociologie suivi de Mon Journal', in Oeuvres completes, sous la direction de G. Busino, tome XI, Genève: Droz.

Passeron, J.-C. (1995), 'Weber et Pareto: La rencontre de la rationalité dans l'analyse sociologique', in L.-A. Gérard-Varet and J.-C. Passeron (eds), Le modéle' et l'enquête. Paris: L'Ecole des Hautes Etudes en Sciences Sociales.

Perrin, G. (1966), La sociologie de Pareto. Paris: PUF.

Rizzello, S. (1997), The Economics of the Mind, Cheltenham, UK and Lyme. USA: Edward Elgar.

Saint-Sermin. B.. Picavet, E., Filleule, R. and Demeurlenaere, P. (1988), Les modiles de l'action, Paris: PUF.

Simon. H. (1945). Administrative Behavior. A Study of Decision-Making Processes in Administrative Organization, New York: Macmillan.

Simon, H. (1955), 'A behavioral model of rational choice', Quarterly Journal of Economics, $60(1), 99-118$.

Simon, H. (1976). 'From substantive to procedural rationality'. in S. Lassis (ed.), Method and Appraisal in Economics, Cambridge: Cambridge University Press, pp. 129-48.

Simon. H. (1978), 'Rationality as process and as product of thought', American Economic Review: 1-16.

Simon, H. (1986). 'Rationality in psychology and economics'. Journal of Business, 59. $209-24$.

Simon, H. (1990), 'Invariants of human behavior', Annual Review' of Psychology' 41. 1-19.

Simon, H. (1996). 'The Sciences of the Artificial, Cambridge. MA: MIT press.

Steiner, P. (1995). 'Pareto et le protectionnisme: l'économie appliquée, la sociologie générale et quelques paradoxes', Revuc Economique, 1240-62.

Steiner, P. (1998). 'Sociologie et économie: la théorie parétienne de l'action économique, Colloque' C. Gide d'Histoire de la pensée économique.

Steiner. P. (1999). 'L'entrepreneur parétien et la théorie de l'action', Revue européc'nne des Sciences Sociales, XXXVII (116), $103-18$.

Wason, P.C. (1969). 'Regression in reasoning?', British Journal of Psychology, 60 (4), $537-46$.

Wason, P.C. and Johnson-Laird. P.N. (1969). 'Natural and contrived experience in a reasoning problem', Quarterly Journal of Experimental Psychology: General. 104 (1), 529.

Wason, P.C. and Johnson-Laird, P.N. (1970). 'A conflict between selecting and evaluating information in an inferential task', British Journal of Experimental Psychology, 61 (1). 63-71. 


\section{Handbook of knowledge and economics}

Wason, P.C. and Golding (1974). 'The language of inconsistency', British Journal of Experimental Psychology, 21 (1), 14-20.

Wetherick, N.E and Gilhooly, K.J. (1990), 'Syllogistic reasoning: effects of premise order', in K.J. Gilhooly, M.T.G. Keane, R.H. Logie and G. Erdos (eds), Lines of Thinking, Vol. 1, New York: John Wiley, pp. 99-108.

Woodworth, R.S. and Sells, S.B. (1935), 'An atmosphere effect in formal syllogistic reasoning'. Journal of Experimental Psychology. 18 (451), 451-60. 